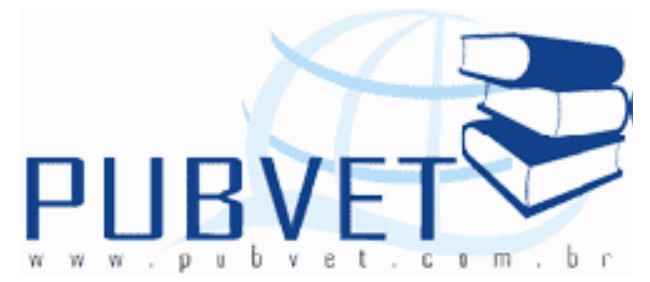

PUBVET, Publicações em Medicina Veterinária e Zootecnia.

\title{
Terço final da gestação suína: utilizar ou não uma dieta diferenciada
}

${ }^{1}$ Zootecnista, Mestrando em Zootecnia - Produção Animal, Av. Alexandre Ferronato, No 1200 Setor Industrial, Sinop-MT, domiciano@zootecnista.com.br 'Zootecnista, IFMT campus São Vicente, BR 364, KM 329, São Vicente da Serra, CEP 78106-970, Santo Antônio do Leverger - MT.

${ }^{3}$ Profa. DZO/IFMT campus São Vicente

${ }^{4}$ Zootecnista, Mestrando em Agricultura Tropical - Nutrição animal, FMEVZ/UFMT, Av. Fernando Corrêa da Costa, n²367, CEP: 78060-900, Cuiabá-MT.

\section{Resumo}

O sucesso da suinocultura está diretamente relacionado com a eficiência no desempenho reprodutivo das matrizes, refletido no número de leitões produzidos/fêmea/ano. Este aumento em produtividade é decorrente do melhoramento genético que estes sofreram nos últimos anos. Simultaneamente, teve-se de ajustar as necessidades nutricionais destas matrizes para suportar o crescimento do feto e da glândula mamária durante, principalmente, o terço final da gestação, com ênfase nas necessidades de proteínas/aminoácidos e energia. No entanto, os programas de alimentação 
DOMICIANO, L.F. et al. Terço final da gestação suína: utilizar ou não uma dieta diferenciada. PUBVET, Londrina, V. 8, N. 9, Ed. 258, Art. 1708, Maio, 2014.

para fêmeas em gestação são baseados em uma única formulação da dieta, com ajustes feitos ao nível de alimentação, tornando-se mais fáceis de aplicar, porém não atendendo às exigências protéico e energética das matrizes, acarretando em desempenho aquém do seu potencial genético. Deste modo, sugerem-se programas de alimentação dividida em duas fases (0-70 dias e 70 dias à parição) para marrãs gestantes com finalidade de melhorar o crescimento fetal, sistema mamário e ganho de proteína materna, sem ganho excessivo de gordura.

Palavras-chave: alimentação, fases de gestação, desempenho reprodutivo.

\section{Swine final third pregnancy: to use or not to use a differentiated diet}

\section{Abstract}

The success of the swine production is directly related to efficiency in reproductive performance matrices, reflected in the number of piglets produced/female/year. This increase in productivity is a result of the genetic improvement they have suffered in recent years. Simultaneously, had to adjust the nutritional needs of these matrices to support the growth of the fetus and mammary gland during mainly the final third of pregnancy, with emphasis on the needs of protein/amino acids and energy. However, the feeding programs for gestation females are based on a single diet formulation, with adjustments to the power level, making it easier to apply, however not meeting the requirements of energy and protein matrices, resulting in performance below their genetic potential. Therefore, we suggest feeding programs in two phases (0-70 days and 70 days to farrowing) for pregnant gilts with the purpose of improving fetal growth, mammary system and maternal protein gain without excessive fat gain.

Keywords: food, stages of pregnancy, reproductive performance. 
DOMICIANO, L.F. et al. Terço final da gestação suína: utilizar ou não uma dieta diferenciada. PUBVET, Londrina, V. 8, N. 9, Ed. 258, Art. 1708, Maio, 2014.

\section{Introdução}

Devido a fatores como, a alta prolificidade e a produção de leitões em um espaço relativamente curto de tempo, a suinocultura apresenta condições de responder ao desafio de produzir proteína animal de alta qualidade, atendendo a demanda do crescimento populacional (Oelke, 2007). Contudo, o desempenho das matrizes é dependente de fatores como genética, manejo, ambiente e nutrição, que irão influenciar diretamente a produtividade da empresa suinícola (Kimet al., 1999). Deste modo, comparação recente revela que o feto suíno é $40 \%$ mais pesados que a40 anos (Kim, 2010).

No entanto, a maioria das fêmeas não são fisiologicamente maduras na primeira gestação e, portanto, há a necessidade de quantidades adequadas de nutrientes para suportar o crescimento uterino e dos fetos (McPherson et al., 2004), das glândulas mamárias (Kim et al., 1999), e síntese do leite (Revell et al, 1998), durante a gestação. Deficiências metabólicas graves para marrãs podem levar a um desempenho reprodutivo insuficiente, baixa lactação, podendo apresentar aumento no intervalo de retorno ao cio, uma redução nas taxas de prenhez e de sobrevivência embrionária (Ji et al., 2005), consequentemente, um abate precoce (Revell et al., 1998).

Contudo, o ganho excessivo de gordura durante a gestação deve ser evitada porque diminui consumo voluntário de alimento durante a lactação (Baker et al., 1969) e diminui a longevidade da porca. Assim, a alimentação gestacional é importante e intimamente relacionada com o desempenho da lactação (Kim e Easter, 2003).

Neste contexto, o presente trabalho de revisão tem por objetivo discutir sobre uma alimentação diferenciada, ao nível proteico e energético da ração, no terço final da gestação de matrizes suínas.

\section{Proteína na fase de gestação}

Considerando o acréscimo de nutrientes em vários tecidos do feto e da placenta, pode-se permitir a real estimativa das necessidades de nutrientes 
DOMICIANO, L.F. et al. Terço final da gestação suína: utilizar ou não uma dieta diferenciada. PUBVET, Londrina, V. 8, N. 9, Ed. 258, Art. 1708, Maio, 2014.

exigidas por marrãs durante a gestação (McPherson et al., 2004). Entretanto, estes resultados descrevem apenas à medida que os tecidos fetais e outros tecidos reprodutivos mudam com duração da gestação e não levam em conta a variação associada ao nível de consumo de ração, o tamanho da leitegada ou outros fatores que influenciam no desenvolvimento fetal (Noblet et al.,1985).

$\mathrm{Na}$ gestação as exigências de proteína e/ou aminoácidos aumentam gradualmente devido à progressiva retenção de proteína dos fetos, estruturas relacionadas, e ao desenvolvimento da glândula mamária (Oelke, 2007).

Kim et al., (2009) relatam que os programas de alimentação convencional proporcionando 8 a $11 \mathrm{~g}$ de lisina digestível (Lys) é insuficiente, pois durante a fase final de gestação,o requerimento aumenta de $6,8 \mathrm{~g} / \mathrm{d}$ para $15,3 \mathrm{~g} / \mathrm{d}$ no terço final de gestação (Figura 1 ). Este aumento na exigência de Lys é explicado pelas mudanças drásticas no ganho de tecido fetal e tecido mamário (Ji et al ., 2006).

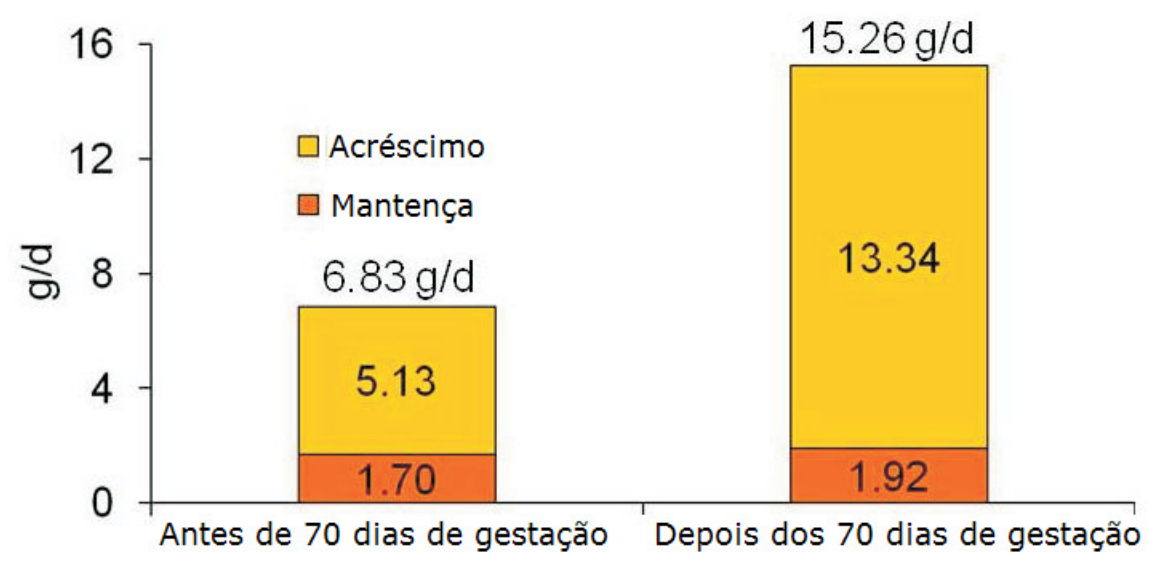

Figura 1. Requerimento de lisina digestível para porcas até os 70 dias e após os 70 dias de gestação. (Adaptado de Kim, 2010).

Ji et al., (2005) avaliando os pesos de fígado, rim e baço de marrãs, constataram que os valores não se alteram durante a gestação (Tabela 1). 
DOMICIANO, L.F. et al. Terço final da gestação suína: utilizar ou não uma dieta diferenciada.

PUBVET, Londrina, V. 8, N. 9, Ed. 258, Art. 1708, Maio, 2014.

Tabela 1. Composição (\%) de vários tecidos maternos em diferentes dias de gestaçãoa

\begin{tabular}{|c|c|c|c|c|c|c|c|c|}
\hline \multirow[b]{2}{*}{ Item } & \multicolumn{8}{|c|}{ Dias de gestação } \\
\hline & $0^{\mathrm{b}}$ & 45 & 60 & 75 & 90 & 102 & 112 & $\mathrm{DP}^{\mathrm{C}}$ \\
\hline \multicolumn{9}{|c|}{ Tecido Muscular } \\
\hline Matéria Seca & 42,01 & 42,7 & 42,5 & 43,1 & 42,8 & 42,6 & 44,6 & 0,5 \\
\hline Proteína Bruta & 39,2 & 39,3 & 39,4 & 38,9 & 39,2 & 40,0 & 38,0 & 0,6 \\
\hline Extrato etéreo & 57,9 & 57,4 & 58,3 & 57,6 & 58,1 & 57,0 & 58,7 & 0,6 \\
\hline Cinza bruta & 1,9 & 1,8 & 1,8 & 1,8 & 1,8 & 1,8 & 1,7 & 0,0 \\
\hline \multicolumn{9}{|l|}{ Pulmão } \\
\hline Matéria Seca & 28,2 & 29,8 & 29,6 & 28,9 & 29,0 & 31,0 & 28,5 & 0,4 \\
\hline Proteína Bruta & 68,4 & 59,0 & 59,4 & 60,0 & 63,9 & 59,9 & 61,0 & 1,2 \\
\hline Extrato etéreo $^{d}$ & 4,0 & 2,8 & 7,0 & 5,6 & 14,1 & 14,1 & 14,3 & 1,6 \\
\hline Cinza bruta & 5,0 & 4,5 & 4,6 & 4,5 & 4,9 & 4,8 & 4,7 & 0,1 \\
\hline \multicolumn{9}{|l|}{$\mathbf{T G I}^{\mathbf{e}}$} \\
\hline Matéria Seca & 26,1 & 27,8 & 28,2 & 27,4 & 26,9 & 27,9 & 28,8 & 0,5 \\
\hline Proteína Bruta & 41,4 & 41,0 & 37,6 & 41,4 & 40,3 & 37,6 & 39,6 & 0,6 \\
\hline Extrato etéreo & 52,8 & 53,7 & 56,4 & 54,5 & 55,3 & 57,8 & 55,9 & 0,7 \\
\hline Cinza bruta ${ }^{f}$ & 2,6 & 2,3 & 2,0 & 2,2 & 2,1 & 1,9 & 1,9 & 0,1 \\
\hline \multicolumn{9}{|l|}{ Vísceras $^{h}$} \\
\hline Matéria Secad & 42,7 & 45,5 & 43,9 & 45,3 & 46,1 & 45,9 & 49,6 & 0,6 \\
\hline Proteína Brutag & 24,7 & 23,3 & 21,1 & 21,8 & 20,3 & 20,7 & 18,2 & 0,6 \\
\hline Extrato etéreo $^{d}$ & 73,7 & 75,9 & 75,9 & 75,5 & 76,3 & 77,0 & 79,2 & 0,5 \\
\hline Cinza bruta ${ }^{f}$ & 1,5 & 1,3 & 1,2 & 1,2 & 1,1 & 1,2 & 1,0 & 0,0 \\
\hline \multicolumn{9}{|l|}{$\begin{array}{l}\text { Utero + } \\
\text { Placenta }\end{array}$} \\
\hline Matéria Seca ${ }^{f}$ & 13,4 & 10,7 & 10,5 & 10,9 & 11,0 & 11,0 & 11,0 & 0,3 \\
\hline Proteína Bruta ${ }^{f}$ & 86,7 & 84,2 & 84,0 & 83,6 & 82,2 & 81,5 & 81,9 & 0,5 \\
\hline Extrato etéreo $^{d}$ & 6,3 & 5,4 & 6,4 & 6,6 & 6,6 & 7,2 & 7,2 & 0,2 \\
\hline Cinza brutag & 7,0 & 7,7 & 7,9 & 8,0 & 7,9 & 8,3 & 8,3 & 0,2 \\
\hline
\end{tabular}

Adaptado de Ji et al., (2005)

${ }^{\text {a }}$ Base na Matéria Seca.

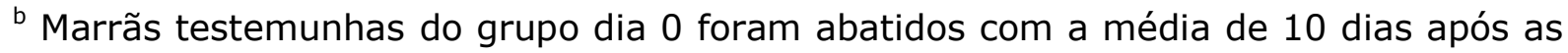
primeiras marrãs criarem.

${ }^{\mathrm{c}}$ Desvio padrão.

${ }^{d}$ Resposta cúbica, $P<0,001$.

e Trato gastrointestinal (TGI) é composto de o estômago vazio, intestino delgado e grosso vazio, ceco e reto.

${ }^{f}$ Resposta linear, $\mathrm{P}<0,001$.

${ }^{9}$ Quadrático, $P<0,05$.

h Vísceras é as partes restantes de órgãos e tecidos após a remoção do pâncreas, fígado, baço, rim, TGI, e do trato reprodutivo. 
DOMICIANO, L.F. et al. Terço final da gestação suína: utilizar ou não uma dieta diferenciada. PUBVET, Londrina, V. 8, N. 9, Ed. 258, Art. 1708, Maio, 2014.

O peso do pâncreas diminuiu linearmente durante a gestação, no entanto, quando os dados do grupo 0 dia foram excluídos da análise de regressão, o peso do pâncreas não se alterou entre 45 e 112 dias de gestação. 0 peso das vísceras que permaneceram, aumentaram durante a gestação. $O$ peso do TGI (Trato Gastrointestinal) diminuiu durante a gestação, possivelmente influenciado pela compressão destes órgãos pela massa fetal em crescimento.

Taxas de deposição proteica diária nos fetos e na glândula mamária aumentam dos 75 dias ao final da gestação. Assim como aumentam as massas de MS, PB, EE na glândula mamária, útero, placenta e massa fetal (Figura 2) durante a gestação (McPherson et al., 2004).

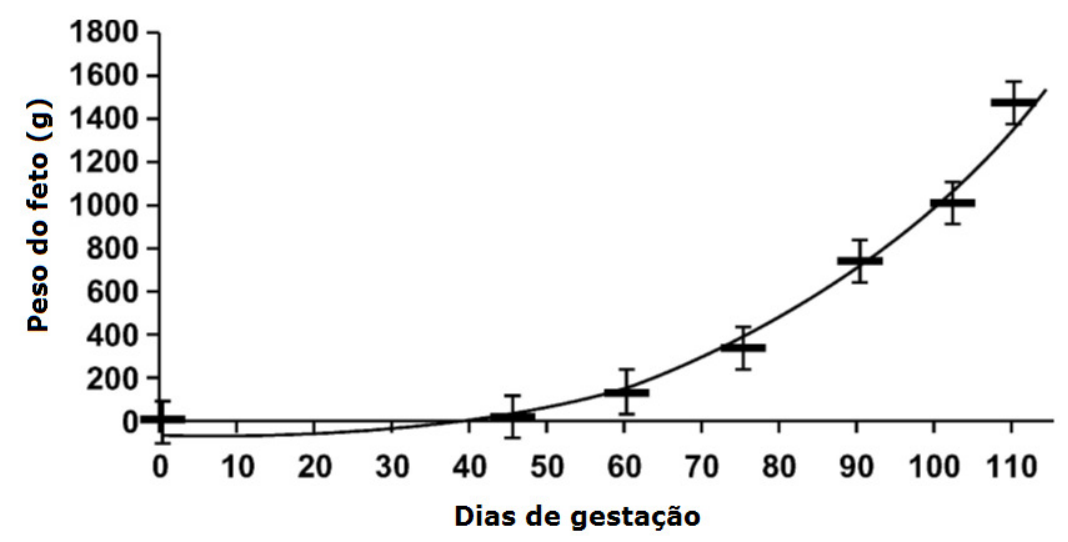

Figura 2. Peso fetal crescente com a evolução da gestação, $R^{2}=0,943$. Adaptado de McPherson et al., (2004).

A restrição proteica em marrãs afeta o peso e conteúdo de RNA do cérebro e peso do fígado de leitões, consequentemente, seu desenvolvimento pós-natal (Atinmo et al., 1974).

McPherson et al., (2004) analisando o crescimento e mudanças de composição de tecidos fetais em suínos, determinaram que o peso fetal foi maior em 110 dias de gestação, e o menor em 45 e 60 dias de gestação (Tabela 2). Peso da carcaça fetal foi maior em 110 dias de gestação e menor em 45 e 60 dias de gestação. Teor de matéria seca da carcaça do feto foi 
DOMICIANO, L.F. et al. Terço final da gestação suína: utilizar ou não uma dieta diferenciada.

PUBVET, Londrina, V. 8, N. 9, Ed. 258, Art. 1708, Maio, 2014.

maior em 102 dias do que nos 75 dias de gestação sem correlação para o dia de gestação. Teor de proteína bruta na carcaça fetal foi maior em 45 e 60 dias e a menor em 110 dias de gestação (Figura 3).

Tabela 2. Peso e composição química do feto e tecido fetal em diferentes dias de gestação

\begin{tabular}{|c|c|c|c|c|c|c|c|}
\hline \multirow[b]{2}{*}{ Variáveis } & \multicolumn{7}{|c|}{ Dias de gestação } \\
\hline & 45 & 60 & 75 & 90 & 102 & 110 & $E P^{a}$ \\
\hline No. de marrãs & 6 & 4 & 5 & 3 & 5 & 4 & - \\
\hline No. de fetos & 79 & 54 & 50 & 33 & 65 & 39 & - \\
\hline Peso do feto $(g)^{b}$ & $21,33^{c}$ & $136,63^{\mathrm{cd}}$ & $334,96^{d}$ & $740,79^{e}$ & $1.005,20^{f}$ & $1.473,20^{g}$ & 99,01 \\
\hline \multicolumn{8}{|l|}{ Carcaça fetal } \\
\hline Peso $(g)^{b}$ & $17,27^{\mathrm{c}}$ & $114,49^{\mathrm{cd}}$ & $288,35^{d}$ & $631,15^{\mathrm{e}}$ & $864,92^{f}$ & $1258,8^{g}$ & 84,81 \\
\hline MS (\%) & $22,50^{\mathrm{cd}}$ & $25,15^{\mathrm{cd}}$ & $20,20^{c}$ & $29,23^{\mathrm{cd}}$ & $31,32^{d}$ & $25,52^{\mathrm{cd}}$ & 0,13 \\
\hline Cinza $(\%)^{\mathrm{h}}$ & $17,07^{c}$ & $21,49^{d}$ & $24,07^{d}$ & $17,83^{c}$ & $17,03^{c}$ & $17,16^{c}$ & 0,83 \\
\hline PB $(\%)^{h}$ & $63,94^{c}$ & $60,41^{c}$ & $57,44^{d}$ & $59,09^{d}$ & $57,93^{d}$ & $51,08^{\mathrm{e}}$ & 1,03 \\
\hline $\mathrm{EE}(\%)^{\mathrm{h}}$ & $15,97^{c}$ & $15,13^{c}$ & $11,67^{d}$ & $14,40^{\mathrm{cd}}$ & $14,01^{\mathrm{cd}}$ & $12,44^{d}$ & 1,33 \\
\hline \multicolumn{8}{|l|}{ TGI Fetal } \\
\hline Peso $(g)^{b}$ & $0,52^{c}$ & $4,08^{\mathrm{cd}}$ & $13,19^{d}$ & $38,19^{e}$ & $55,39^{f}$ & $90,63^{9}$ & 6,01 \\
\hline MS (\%) & - & 20,48 & 16,10 & 21,91 & 17,97 & 23,20 & 0,14 \\
\hline Cinza $(\%)^{\mathrm{h}}$ & - & $9,26^{\mathrm{c}}$ & $8,62^{c}$ & $8,31^{d}$ & $8,49^{d}$ & $8,28^{d}$ & 0,14 \\
\hline PB $(\%)^{h}$ & - & 72,10 & 70,89 & 71 & 71,15 & 72,79 & 0,39 \\
\hline $\mathrm{EE}(\%)^{\mathrm{h}}$ & - & 15,33 & 15,44 & 15,23 & 14,61 & 13,11 & 1,49 \\
\hline \multicolumn{8}{|l|}{ Fígado Fetal } \\
\hline Peso $(g)^{b}$ & $2,19^{\mathrm{C}}$ & $8,93^{\mathrm{cd}}$ & $14,47^{d}$ & $27,84^{\mathrm{e}}$ & $29,51^{\mathrm{e}}$ & $44,06^{f}$ & 2,95 \\
\hline MS (\%) & 23,52 & 26,44 & 20,89 & 31,72 & 25,03 & 29,42 & 0,13 \\
\hline Cinza $(\%)^{\mathrm{h}}$ & 8,33 & 7,61 & 6,75 & 6,23 & 8,42 & 8,28 & 0,42 \\
\hline PB $(\%)^{h}$ & $75,83^{c}$ & $78,94^{c}$ & $78,95^{c}$ & $72,21^{\mathrm{cd}}$ & $67,58^{\mathrm{cd}}$ & $58,38^{d}$ & 1,89 \\
\hline$E E(\%)^{h}$ & - & - & - & $19.46^{c}$ & $16,55^{c}$ & $24,80^{d}$ & 1,48 \\
\hline \multicolumn{8}{|l|}{ Coração Fetal } \\
\hline Peso $(g)^{b}$ & $0,28^{c}$ & $1,06^{\mathrm{cd}}$ & $2,31^{d}$ & $6,46^{\mathrm{e}}$ & $8,88^{f}$ & $12,08^{\mathrm{g}}$ & 0,84 \\
\hline MS (\%) & - & $21,49^{\mathrm{cd}}$ & $16,40^{c}$ & $23,01^{\mathrm{cd}}$ & $19,56^{\mathrm{cd}}$ & $25,75^{d}$ & 0,13 \\
\hline Cinza $(\%)^{\mathrm{h}}$ & - & $7,56^{\mathrm{c}}$ & $6,61^{\mathrm{cd}}$ & $6,76^{\mathrm{cd}}$ & $6,33^{\mathrm{cd}}$ & $6,31^{d}$ & 0,14 \\
\hline PB $(\%)^{h}$ & - & $77,37^{\mathrm{cd}}$ & $71,10^{c}$ & $76,82^{\mathrm{cd}}$ & $77,87^{d}$ & $76,89^{\mathrm{cd}}$ & 0,89 \\
\hline \multicolumn{8}{|l|}{ Pulmão Fetal } \\
\hline Peso $(g)^{b}$ & $0,51^{\mathrm{c}}$ & $5,37^{\mathrm{cd}}$ & $11,25^{d}$ & $25,23^{e}$ & $33,24^{f}$ & $49,68^{g}$ & 3,35 \\
\hline MS (\%) & 25,43 & 20,13 & 24,02 & 19,89 & 18,04 & 26,59 & 0,18 \\
\hline Cinza $(\%)^{\mathrm{h}}$ & $8,43^{d}$ & $8,52^{c}$ & $7,66^{\mathrm{cd}}$ & $6,78^{d}$ & $7,11^{d}$ & $7,28^{\mathrm{cd}}$ & 0,22 \\
\hline PB $(\%)^{h}$ & $75,01^{c}$ & $65,10^{d}$ & $62,73^{d}$ & $69,38^{\mathrm{e}}$ & $69,55^{\mathrm{e}}$ & $70,38^{\mathrm{e}}$ & 0,91 \\
\hline
\end{tabular}

Continua... 
DOMICIANO, L.F. et al. Terço final da gestação suína: utilizar ou não uma dieta diferenciada.

PUBVET, Londrina, V. 8, N. 9, Ed. 258, Art. 1708, Maio, 2014.

Continuação...

\section{Rim Fetal}

Peso $(g)^{b}$

MS (\%)

Cinza $(\%)^{\mathrm{h}}$

PB $(\%)^{\mathrm{h}}$

Cérebro Fetal

Peso $(g)^{b}$

MS (\%)

Cinza $(\%)^{\mathrm{h}}$

PB $(\%)^{\mathrm{h}}$

EE $(\%)^{\mathrm{h}}$

Placenta

Peso $(\mathrm{g})^{\mathrm{b}}$

MS (\%)

$$
\begin{array}{ccccccc}
0,57^{\mathrm{c}} & 2,71^{\mathrm{d}} & 5,04^{\mathrm{d}} & 10,83^{\mathrm{e}} & 11,75^{\mathrm{e}} & 15,74^{\mathrm{f}} & 1,09 \\
- & 21,25 & 19,23 & 23,13 & 17,89 & 24,97 & 0,14 \\
- & 9,11^{\mathrm{c}} & 7,25^{\mathrm{de}} & 7,40^{\mathrm{d}} & 7,13^{\mathrm{de}} & 6,59^{\mathrm{e}} & 0,20 \\
- & 71,92^{\mathrm{c}} & 73,28^{\text {cd }} & 74,82^{\mathrm{d}} & 74,24^{\text {cd }} & 72,98^{\text {cd }} & 0,38
\end{array}
$$

Cinza $(\%)^{\mathrm{h}}$

$\begin{array}{cc}- & 3,13^{\mathrm{c}} \\ - & 18,12 \\ - & 11,82^{\mathrm{c}} \\ - & 63,23^{\mathrm{c}} \\ - & -\end{array}$

$3,57^{\mathrm{c}} \quad 9,88^{\mathrm{cd}}$

$17,45^{\mathrm{d}}$

$25,46^{\mathrm{e}}$

2,15

26,35

19,08

18,85

17,95

0,24

$10,96^{\mathrm{c}}$

$9,46^{\text {cd }}$

$7,28^{\mathrm{d}}$

$8,30^{\text {cd }}$

0,46

$58,59^{\mathrm{d}}$

$58,90^{\mathrm{d}}$

$59,11^{\text {d }}$

$58,44^{\mathrm{d}}$

0,46

31,34

30,49

30,48

$32,22 \quad 2,40$

Adaptado de McPhersonet al., (2004)

${ }^{a}$ Erro Padrão da Média

bDentro da mesma linha há um aumento de peso de acordo com a gestação progredia $(P<0,001)$

$c, d, e, f, g$ Dentro da mesma linha letras iguais não se diferem entre si $(P<0,005)$

hase na Matéria Seca.

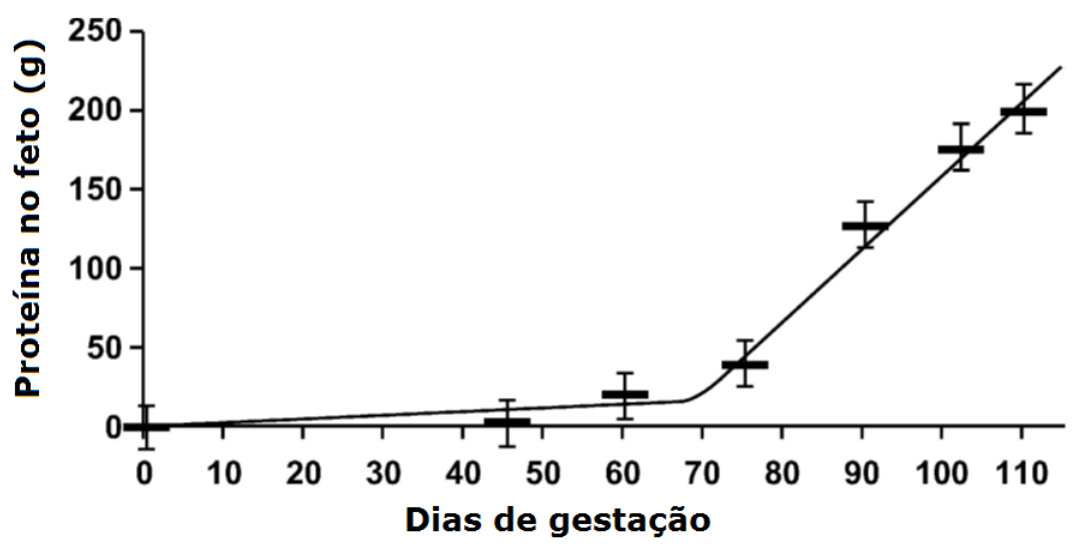

Figura 3. Ponto de transição do teor de proteína fetal ( $\mathrm{g}$ ) ocorreu em 68,5 dias de gestação $\left(R^{2}=0,988\right)$, mostrando que o aumento de proteína fetal ocorre a partir de então. Adaptado de McPherson et.al., (2004). 
DOMICIANO, L.F. et al. Terço final da gestação suína: utilizar ou não uma dieta diferenciada.

PUBVET, Londrina, V. 8, N. 9, Ed. 258, Art. 1708, Maio, 2014.

Kim et al., (2009) ressaltam que o retardamento do crescimento fetal ocorre principalmente depois dos 60 dias de gestação (Figura 4). Isso devido a máxima deposição proteica para o crescimento fetal (McPherson et. al., 2004).

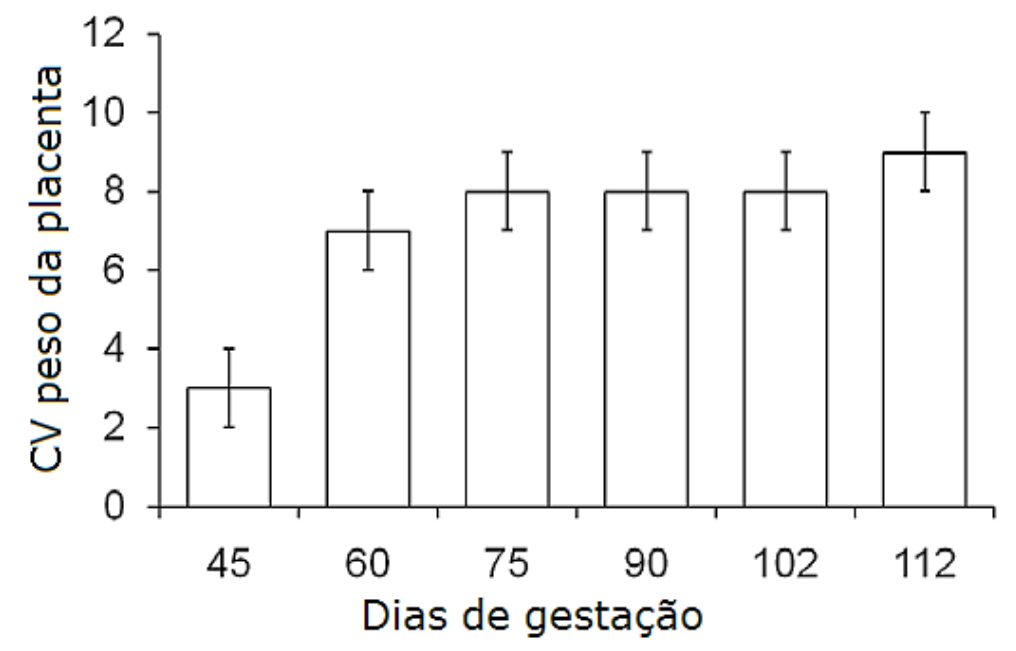

Figura 4. Variações de peso entre fetos dentro da placenta em dias diferentes de gestação. A variação de peso de placenta foi expressada como coeficiente de variação [CV (\%)] para cada placenta em dias diferentes de gestação. Adaptado de Kim et al., (2009).

De forma análoga, o peso fetal diminuiu linearmente para fetos mais próximos a cérvix comparados aos mais distantes nos córneos uterinos em 102 e 112 dias de gestação (Figura 5). Deste modo, o fornecimento limitado de proteínas/aminoácido para porcas pode acarretar não somente no crescimento de fetos, mas também em parições desuniformes, aumentando a variação de peso dos leitões. 
DOMICIANO, L.F. et al. Terço final da gestação suína: utilizar ou não uma dieta diferenciada.

PUBVET, Londrina, V. 8, N. 9, Ed. 258, Art. 1708, Maio, 2014.

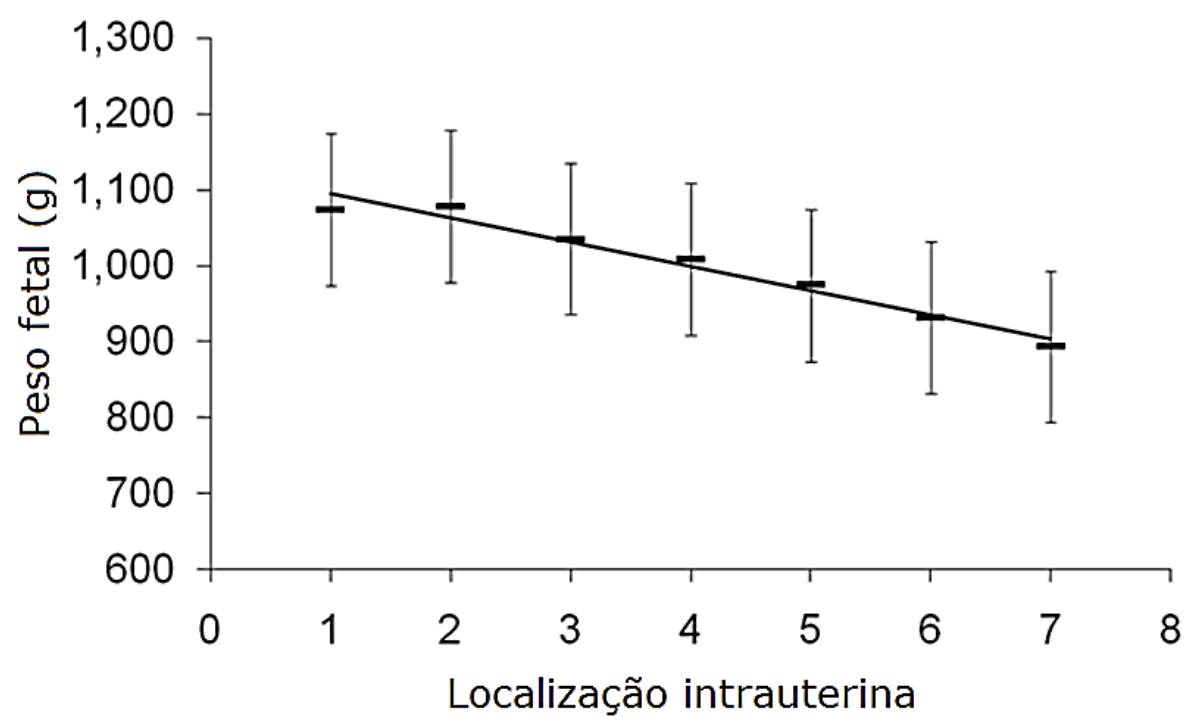

Figura 5.Variações de peso entre fetos em 102 dias de gestação. Local intrauterino: 1 indica extremidade anterior (i.e., junção da tuba uterina) e 7 indicam extremidade posterior (i.e., cérvix). Adaptado de Kim et al., (2009).

No entanto, Clowes et al.,(2003) não encontram benefícios produtivos e reprodutivos para porcas alimentadas com três níveis de proteína durante a gestação. Mesmo assim, os autores recomendam tal prática pela redução da excreção de nitrogênio total e emissão de amônia, o que pode contribuir para maior produtividade animal e atendimento da legislação ambiental.

\section{Energia na fase de gestação}

O fornecimento de energia para as porcas durante a gestação deve ser modulado de acordo com a mobilização das reservas corporais durante a lactação anterior. Obviamente, este não é o caso de matrizes de primeiro parto, sendo que, para estes animais deve-se proporcionar um correto manejo nutricional durante o seu crescimento, para ter um ótimo desenvolvimento reprodutivo (Oelke, 2007).

Noblet et al., (1985) avaliando os efeitos do nível de consumo de ração, com alta e baixa energia metabolizável (EM), sobre o crescimento e a composição química do útero gravídico e tecido mamário em vários estágios de 
DOMICIANO, L.F. et al. Terço final da gestação suína: utilizar ou não uma dieta diferenciada.

PUBVET, Londrina, V. 8, N. 9, Ed. 258, Art. 1708, Maio, 2014.

gestação (Tabela 3), encontraram aumento significativo no peso fresco (Figura 6) e tamanhos da leitegada. Com o aumento na fase de gestação, os teores médios de MS do útero gravídico aumentaram do dia 50 para os dias 90 e 110 de gestação (Figura 6).

Tabela 3. Peso $(\mathrm{g})$ dos tecidos uterinos de marrãs gestantes em relação ao estágio da gestação e do nível de ingestão de energia. Valores médios com seu desvio padrão (DP).

\begin{tabular}{cccccccccc}
\hline \hline $\begin{array}{c}\text { Estagio de } \\
\text { gestação(d) }\end{array}$ & \multicolumn{2}{c}{ Feto } & \multicolumn{2}{c}{ Placenta } & \multicolumn{2}{c}{ Fluidos } & \multicolumn{3}{c}{$\begin{array}{c}\text { Úteros } \\
\text { vazios }\end{array}$} \\
\hline Média & DP & Média & DP & Média & DP & Média & DP & Média & DP \\
\hline \multicolumn{8}{c}{ Baixa ingestão (4,78 Mcal EM/dia) } \\
\hline 51 & 1 & 572 & 123 & 2018 & 453 & 2320 & 566 & 1615 & 195 \\
79 & 1 & 4554 & 562 & 3161 & 198 & 5232 & 822 & 2253 & 105 \\
102 & 3 & 9918 & 741 & 3817 & 390 & 3722 & 320 & 2663 & 272 \\
\hline \multicolumn{8}{c}{ Alta ingestão (7,16 Mcal EM*/d) } \\
\hline 53 & 2 & 856 & 131 & 2366 & 181 & 3320 & 629 & 1975 & 197 \\
72 & 2 & 3338 & 508 & 3085 & 346 & 5482 & 1238 & 2119 & 230 \\
103 & 2 & 12781 & 455 & 4906 & 315 & 3370 & 366 & 3433 & 198 \\
\hline
\end{tabular}

Adaptado de Noblet et al., (1985)

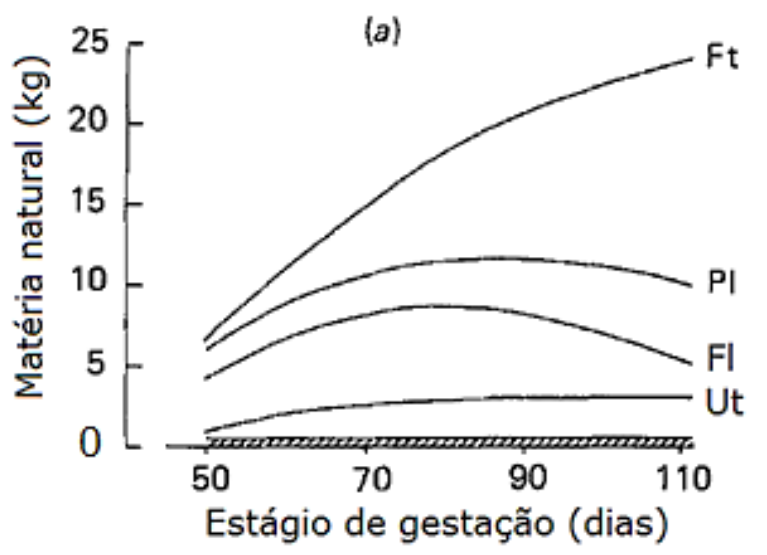

Continua...

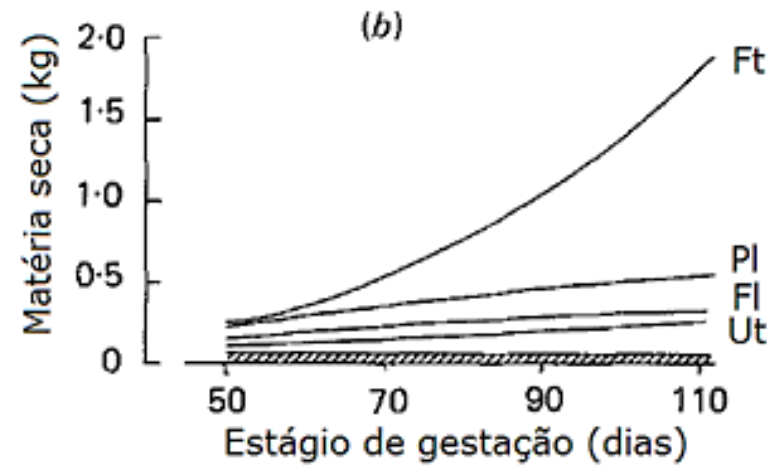

Estágio de gestação (dias) 

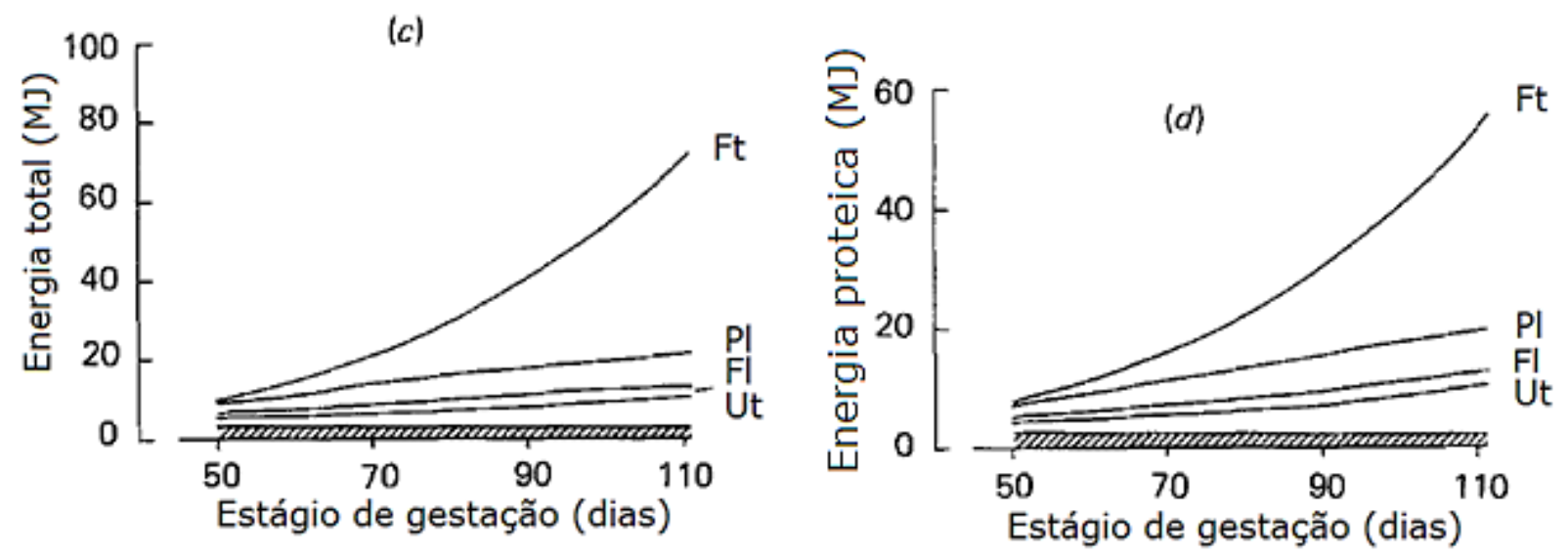

Figura 6. Previsões do crescimento e desenvolvimento do útero gravídico e tecidos e seus componente na marrã gestante. Valores foram calculados para uma energia metabolizável (EM) ingestão de $7,16 \mathrm{Mcal} / \mathrm{d}$ e para um tamanho da ninhada de doze leitões. (a), matéria natural, (b), matéria seca, (c), energia total; (d) proteína; $\mathrm{Ft}=$ feto; $\mathrm{Pl}=$ placenta; $\mathrm{Fl}=$ fluidos; Ut=útero vazio. Adaptado de Noblet et al., (1985)

Os autores calcularam que entre os 50 e 110 dias de gestação a exigência de EM para a reprodução aumentou de 3 para $12 \%$ do consumo de energia para mantença e reprodução (Tabela 4).

Tabela 4. As taxas previstas de energia ( $\mathrm{kcal} / \mathrm{dia}$ ) e proteína ( $\mathrm{g} / \mathrm{dia}$ ) acréscimo no tecido reprodutivo das marrãs prenhes, divididas em componentes do tecido uterino e mamário (Os valores foram calculados para um tamanho da ninhada de doze leitões e energia metabolizável (EM) a ingestão de 4,78 e 7,16Mcal/d).

\begin{tabular}{ccccccc}
\hline \hline \multirow{2}{*}{$\begin{array}{c}\text { Estagio de } \\
\text { gestação(d) }\end{array}$} & \multicolumn{1}{c}{ Útero Gravídico } & \multicolumn{2}{c}{ Tecido Mamário } & \multicolumn{2}{c}{ Total } \\
\cline { 2 - 7 } & Energia & Proteína & Energia & Proteína & Energia & Proteína \\
\hline \multicolumn{5}{c}{ Baixa ingestão } & $\mathbf{( 4 , 7 8}$ Mcal EM/dia) & \\
\hline 50 & 349 & 11 & 141 & 1 & 490 & 12 \\
70 & 624 & 19 & 190 & 2 & 814 & 21 \\
90 & 1030 & 32 & 259 & 4 & 1289 & 36 \\
100 & 1289 & 39 & 304 & 8 & 1593 & 47 \\
110 & 1586 & 48 & 357 & 17 & 1943 & 65 \\
\hline
\end{tabular}

Continua... 
DOMICIANO, L.F. et al. Terço final da gestação suína: utilizar ou não uma dieta diferenciada.

PUBVET, Londrina, V. 8, N. 9, Ed. 258, Art. 1708, Maio, 2014.

\begin{tabular}{ccccccc}
\multicolumn{7}{c}{ Alta ingestão } \\
\hline 50 & 391 & 13 & 244 & 1 & 635 & 14 \\
70 & 724 & 24 & 330 & 2 & 1054 & 26 \\
90 & 1238 & 40 & 449 & 7 & 1687 & 47 \\
100 & 1577 & 51 & 526 & 13 & 2103 & 64 \\
110 & 1976 & 64 & 619 & 25 & 2595 & 89 \\
\hline
\end{tabular}

Adaptado de Noblet et al., (1985)

Assim, a nutrição durante a gestação deve maximizar a retenção proteica e garantir uma adequada deposição de gordura. Essa estratégia maximiza a liberação de insulina, minimiza os níveis de glucagon, aumentando o consumo voluntário de ração durante a lactação (Kim e Easter, 2006).

Noblet et al. (1990) afirmam que requisitos diários de EM são particularmente elevados (15 a $20 \mathrm{Mcal} / \mathrm{dia}$ ) e, geralmente, não são atendidas por consumo voluntário de alimento, sendo que a mobilização de gordura corporal no final da gestação é de 7,3 Mcal ED/dia. Ressaltando-se que porcas com alimentação à vontade durante a gestação podem apresentar-se muito pesadas e com excesso de gordura corporal no momento do parto. Isso implica negativamente sobre o consumo de alimento durante a lactação (Abreu et al., 2005).

Matrizes alimentadas próximo a mantença apresentaram um balanço energético negativo na gestação seguinte (Noblet et al., 1990). Para Cole (1990), 9,5 Mcal ED/dia, do $90^{\circ}$ dia de gestação até o parto, são necessárias para manter a espessura de toucinho no ponto P2 em matrizes. Corroborando com estes resultados, Hughes (1993) também observou que a espessura de toucinho no ponto P2 abaixo de $12 \mathrm{~mm}$, no momento do parto, e abaixo de 10 $\mathrm{mm}$, no desmame,comprometeu o intervalo desmame-cio e reduziu o tamanho da próxima leitegada. 
DOMICIANO, L.F. et al. Terço final da gestação suína: utilizar ou não uma dieta diferenciada.

PUBVET, Londrina, V. 8, N. 9, Ed. 258, Art. 1708, Maio, 2014.

\section{Considerações finais}

Atuais programas de alimentação para fêmeas em gestação são baseados em uma única formulação da dieta, com ajustes feitos ao nível de alimentação, ou seja, na quantidade diária fornecida. Estes programas são simples e fáceis de aplicar, no entanto, não fornecendo proteínas e energia suficientes durante o período final da gestação, causando aumento do estresse metabólico das porcas.

Estratégia de alimentação ideal para matrizes em gestação deve ser suficientemente flexível para ajustar ao subsídio de nutrientes de acordo com as necessidades para o crescimento, tanto do útero quanto fetal. Deste modo, os resultados dos estudos abordados, sugerem a necessidade de um programa de alimentação em duas fases (0-70 dias e 70 dias à parição) para marrãs gestantes com finalidade de melhorar o crescimento fetal e ganho de proteína materna sem ganho excessivo de gordura.

Diversas informações sobre exigências de energia e sua utilização em porcas gestantes estão disponíveis, o que nos permite desenvolver recomendações para uma série de situações. Geralmente, as recomendações de energia devem ser arquitetadas de acordo com o estado gestacional, desempenho da lactação anterior, e os objetivos para o crescimento do tecido uterino, bem como a mudanças na composição corporal sobre gestações sucessivas, pois durante a gestação, as necessidades energéticas variam de acordo com as condições de instalação, o ganho de peso desejado e aumento na lactação. Portanto, o planejamento da alimentação durante a gestação não pode ser considerado com base no rebanho, mas devem ser adaptadas individualmente em quantidade e/ou qualidade, a fim de reduzir a variação na composição corporal que existe entre porcas, evidenciado pelos elevados requisitos de energia durante a lactação e, geralmente, não são atendidas pela ingestão voluntária de alimentos. Deste modo, a recomendação mais adequada é evitar mudanças no corpo, falta ou excesso de peso ao longo dos ciclos reprodutivos, particularmente durante a lactação e mais atenção deve então 
DOMICIANO, L.F. et al. Terço final da gestação suína: utilizar ou não uma dieta diferenciada.

PUBVET, Londrina, V. 8, N. 9, Ed. 258, Art. 1708, Maio, 2014.

ser dada para a regulação do consumo de ração das porcas em fase final de gestação e lactação.

\section{Referências}

ABREU, M.L.T.; DONZELE, J.L.; OLIVEIRA, R.F.M. Exigências e Manejo Nutricionais de Matrizes Suínas Gestantes e Lactantes. In: IV SEMINÁRIO INTERNACIONAL DE AVES E SUÍNOS AVESUI 2005. SUINOCULTURA: NUTRIÇÃO E MANEJO, 2005, Florianópolis. Anais.Florianópolis - SC, p.33- 59.2005.

ATINMO, T.; POND, W. G. e BARNES, R. H. Effect of maternal energy vs. protein restriction on growth anddevelopment of progeny in swine.Journal of Animal Science.,v.39, p.703-711, 1974.

BAKER, D. H., D. E. BECKER, H. W. NORTON, C. E. SASSE, A. H. JENSEN, and B. G. Harmon. Reproductive performance and progeny development in swine as influenced by feed intake during pregnancy. The Journal of Nutrition.v.97.p.489-495. 1969.

CLOWES, E.J.; KIRKWOOD, R.; CEGIELSKI, A.; AHERNE, F.X. Phase-feeding protein to gestating sows over three parities reduced nitrogen excretion without affecting sow performance. Livestock Production Science, v.81, p.235-246, 2003.

COLE, D. J. A. Nutritional strategies to optimize reproduction in pigs.Journal of Reproduction and Fertility.Supl 40:67.1990.

HUGHES, P. E. The effect of food level during lactation and early gestation on the reproductive performance of maturesows.Animal Production.57:437, 1993.

JI, F.; WU, G.; BLANTON, J.R.; KIM, S.W. Changes in weight and composition in various tissues of pregnant gilts and their nutritional implications.Journal of Animal Science.v.83, p.366-375, 2005.

KIM, S. W. Recent advances in sow nutrition. Revista Brasileira de Zootecnia, v.39, p.303310, 2010.

KIM, S. W., e EASTER, R. A..Amino acid utilization for reproduction in sows. P. 203-222, 2003.In: Amino Acids in Animal Nutrition. 2ed. J. P. F. D Mello, ed. CAB International, Wallingford, U.K.2003.

KIM, S. W.;HURLEY,W. L.;HAN,I. K.;STEIN,H. H.; EASTER, R. A.Effect ofnutrient intake on mammary gland growth in lactating sows. Journal of Animal Science.v.77, p.3304-3315, 1999.

MCPHERSON, R. L., F. JI, G. WU, J. R. BLANTON, And S. W. KIM. Fetal growth and compositional changes of fetal tissues in pigs.Journal of Animal Science.v.82, p.30143020. 2004.

NOBLET, J. CLOSET, W. H. and HEAVENS, R. P. Studies on the energy metabolism of the pregnant sow.British Journal of Nutrition, v.53. p.251-265. 1985. 
NOBLET, J., J. Y. DOURMAD, and M. ETIENNE.Energy utilization in pregnant and lactating sows: Modeling of energy requirements. Journal of Animal Science.v.68, p.562. 1990.

NOBLET, J.; DOURMAD, J. Y.; ETIENNE, M. AND LE DIVIDICH, J. Energy metabolism in pregnant sows and newborn pigs.Journalof Animal Science. v.75. p.2708-2714. 1997.

OELKE, A. C. Níveis de lisina digestível em dietas de fêmeas suínas primíparas em lactação. Dissertação (Mestrado) 2007. Ciências Veterinárias, Curso de Pós- Graduação em Ciências Veterinárias. Universidade Federal do Paraná. Curitiba, 2007.

REVELL, D.K.; WILLIAMS, I.H.; MULLAN, B.P. et al. Bodycomposition at farrowing and nutrition during lactation affectthe performance of primiparous sows: II. Milk composition, milk yield, and pig growth. Journal of Animal Science, v.76,p.1738 1743, 1998. 